\title{
Accuracy and Adequacy of Percutaneous CT-Guided Fine Needle Aspiration Biopsy in Cavitary Pulmonary Lesions
}

\author{
AHMED I. EBEED, M.D.*; AYMAN ELSAKA, M.D.** and YOMNA ZAMZAM, M.D.** \\ The Department of Diagnostic and Interventional Radiology, Faculty of Medicine, Kafr El-Sheikh University* and \\ The Department of Pathology, Faculty of Medicine, Tanta University**
}

\begin{abstract}
Background: Lung cavity is not a specific radiological finding, Computed Tomography (CT)-guided lung biopsy is a reliable method of diagnosing lung lesions cytologically, Fine Needle Aspiration Biopsy (FNAB) is considered as a relatively safe procedure $\&$ accurate procedure with less complication rate.
\end{abstract}

Taking in consideration the serious complication of CT guided lung biopsy and the need for obtaining adequate sample to get benefit of the recent success in targeted therapy of nonsmall cell lung carcinoma and lung adenocarcinoma.

Aim of Study: The aim of this study is to evaluate the accuracy of CT guided fine needle biopsy in cavitary pulmonary lesions and to establish technical parameters to bridge the gap between diagnostic accuracy and adequacy of CT guided fine needle biopsy in cavitary pulmonary lesions.

Patients and Methods: 52 patients with lung cavities were included (29 male and 23 female) with age (mean \pm SD) of $56 \pm 12.4$ years. Sampling of the maximal wall thickness of the lesion. Aspirated specimens were submitted on positively charged glass slides and the remainder fixed in $95 \%$ alcohol. A pathologist performed rapid an onsite preliminary diagnosis and material triage. In all 52 cases Fine Needle Aspirations (FNA) for cytology were obtained, Samples for microbiology were obtained in 10 cases. The results categorized into 4 diagnostic groups malignant, Benign specific, Benign nonspecific, and non diagnostic.

Results: Histological examinations revealed over all sensitivity (39/41) and specificity (9/10), of CT guided FNAB for diagnosing the malignancy.

In 6 cases, molecular studies were requested, positively charged glass slides and cell block paraffin-embedded tissue was used in all cases in $66.6 \%$ of the cases all requested molecular tests could be done, in $16.7 \%$ the material were sufficient for only some studies while in $16.7 \%$ there was no sufficient material for any test. In some cases Epidermal Growth Factor Receptor [EGFR], Anaplastic Lymphoma Kinase $[\mathrm{ALK}]$ testing were requested and successfully performed.

Correspondence to: Dr. Ahmed I. Ebeed,

The Department of Diagnostic and Interventional Radiology, Faculty of Medicine, Kafr El-Sheikh University
Conclusion: CT-guided fine needle biopsy of cavitary lung lesions combined with rapid on site pathological evaluation increase the accuracy and bridge the gap between accuracy and adequacy to provide adequate tissue for molecular testing from the small size sample.

Key Words: Cavitary lung lesion - Intervention radiology CT guided biopsy.

\section{Introduction}

CAVITARY lung lesions are gas-filled lung area surrounded by thick walls within a pulmonary mass, nodule, or consolidation [1] . Lung cavity is not a specific finding which can be observed in many malignant and benign lung lesions. Radiological appearance of benign and malignant lung cavity are commonly overlapped, therefore cannot always create a correct diagnosis of cavitary pulmonary lesions before treatment plan [1].

CT-guided lung biopsy is a reliable method of diagnosing lung lesions cytologically especially in advanced disease and when patient is not candidates for surgery, however large Core Needle Biopsy (CNB) provides tissue of good quality for histopathologic analysis compared to fine needle biopsy the complications associated with CNB, e.g. pneumothorax, hemoptysis or massive peritumoral hemorrhage, are of major concern [2,3] especially with cavitary lung lesions where significant degrees of pneumothorax, hemoptysis, peritumoral hemorrhage or even air embolism which can be life-threatening and require urgent interventions. In such situation FNAB is considered as an alternative relatively safe procedure with the same accuracy as large core needle biopsy with less complication rate [4].

Taking in consideration the serious complication of CT guided lung biopsy and the need for obtaining 
adequate sample to get benefit of the recent success in targeted therapy of non-small cell lung carcinoma and lung adenocarcinoma where the pathologist expected to be able to identify lung lesions microscopically using restricted tissue and in the case of malignant lesion, make sure that he has enough tissue remains for further molecular analysis such as Epidermal Growth Factor Receptor [EGFR], Anaplastic Lymphoma Kinase [ALK]) which guide treatment $[\mathbf{5 , 6}]$.

Therefore multidisciplinary approach with direct communication between the interventional radiologist, pathologist, and the clinician to provide special care differ from the past when fewer tests were required on the sample, to fill the gap between accuracy and adequacy of the small sample tissue with obtaining adequate material during guidance biopsy, careful treatment with sample, avoid abuse of molecular studies panels which may exhaust the sample as well as the wise choice of immunestains to sub classify tumors [7]

\section{Patients and Methods}

This prospective study was performed during the period between January 2018 and June 2019.

52 patients with pulmonary cavitary lesions were referred from out patient chest clinic to Intervention Radiology Unit for guidance biopsy (29 male and 23 female) with age (mean \pm SD) of $56 \pm$ 12.4 years, ethical committee approval was attained.

The procedures were guided by a 16 MDCT scanner, slice thickness $2.5-5 \mathrm{~mm}, \mathrm{kV} \mathrm{100-140,} \mathrm{and}$ mA 100-260.

\section{Inclusion criteria:}

Patient presented with suspicious lung cavities (thick irregular wall with solid component).

\section{Exclusion criteria:}

- Lung lesions less than $5 \mathrm{~mm}$.

- Uncooperative patients.

- Cavities less than $1.0 \mathrm{~cm}$ away from the pulmonary hilum,

- Patients with abnormal coagulation profile.

- Patients with pulmonary vascular lesion or pulmonary hypertension.

Position of the patient: Prone, decubitus or supine, depending on the location of the lesion.
Crossing large vessels, fissures, or bullae should be avoided.

Root of entry and angle of the needle is measured along the $\mathrm{z}$ plane and Protractor calibrated with spirit level is used during needle entry to avoid visualization bias.

The maximal wall thickness of the lesion was targeted, when accessible.

Narrow caliber co axial Chiba needle was used.

Aspirated materials were introduced on glass slides two of them are positively charged glass slides.

Staining one or two slides, fixing the remainder in $95 \%$ alcohol and processing using diff-quick stain for rapid onsite examination, done by a pathologist to perform diagnosis and material triage.

In cases of infection, further aspirates were obtained and submitted for microbiology and culture study.

In cases of malignancy, additional aspirates for cell block were obtained to assure adequate material and preserved in formalin $10 \%$.

Intra-cavitary fluid was also aspirated.

At the end of the procedure, CT cuts were taken to rule out complication.

\section{Diagnostic criteria:}

1-Malignant (where malignant cells clearly detected in the aspirate).

2- Benign specific (where specific benign cells detected in the aspirate).

3- Benign nonspecific (where no malignant cells detected, inflammatory aspirates).

4- And non diagnostic (where non conclusive aspirates whether benign or malignant aspirate).

For the non diagnostic series the final diagnosis was made by either surgery, or clinical and radiological follow-up (3-6 months).

Material adequacy for molecular testing may be:

- Adequate material for all needed immune-histochemical marker including those specific for target therapy.

- Adequate material for some needed tests.

- Inadequate material for any tests (just malignant cells was detected). 


\section{Statistical methods:}

Statistical analysis was done by IBM personal computer (SPSS Inc., Chicago, Illinois, USA) software package version 25.0. Two types of statistics were done: Descriptive statistics, for example, percentage, mean, SD, and range, and analytic statistics. $p$-value less than 0.05 regarded statistically significant.

\section{Results}

52 patient were included, $18(34.6 \%)$ were women and $34(65.4 \%)$ were men, $5(9.6 \%)$ non smoker, 10 (19.2\%) ex smoker \& $37(71.1 \%)$ current smoker.

The mean age was 55 years.

Lesion size was ranged from $0.6 \mathrm{~cm}$ to $8.6 \mathrm{~cm}$, with a mean of $3.5 \mathrm{~cm}$.

In $57.6 \%$ of cases $(30 / 52)$, the lesions were single. In $42.4 \%$ of cases $(22 / 52)$, the lesions were multiple.
Pathological results Fig. (1):

36 aspirates were diagnosed as malignancies, including:

- 15 cases adenocarcinomas Fig. (3).

- 11 cases squamous cell carcinoma.

- 4 cases small cell carcinomas Fig. (4).

- 4 cases Non-Small Cell Carcinomas (NSCLC).

- 2 cases metastatic lung cancer Fig. (2).

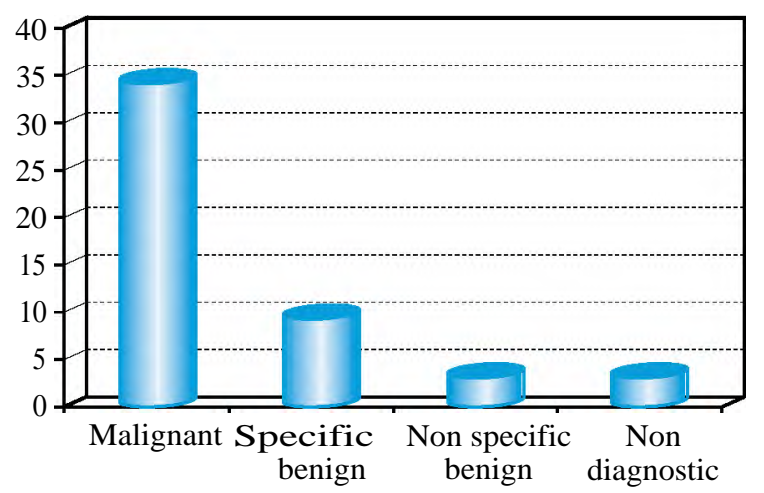

Fig. (1): The diagnostic accuracy of CT guided FNAB.

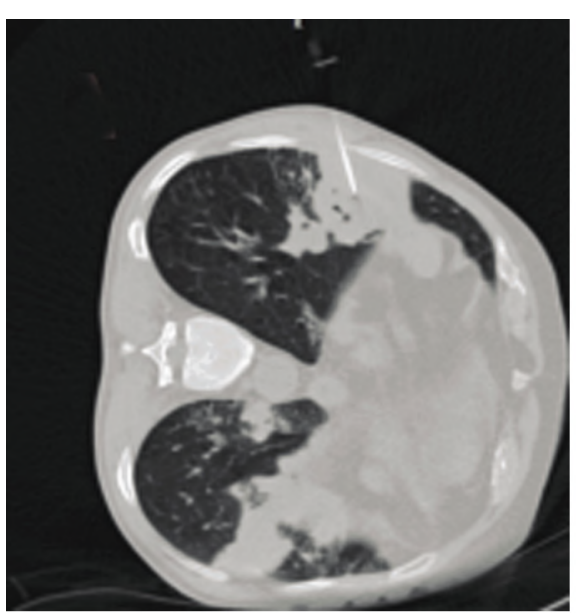

(A)

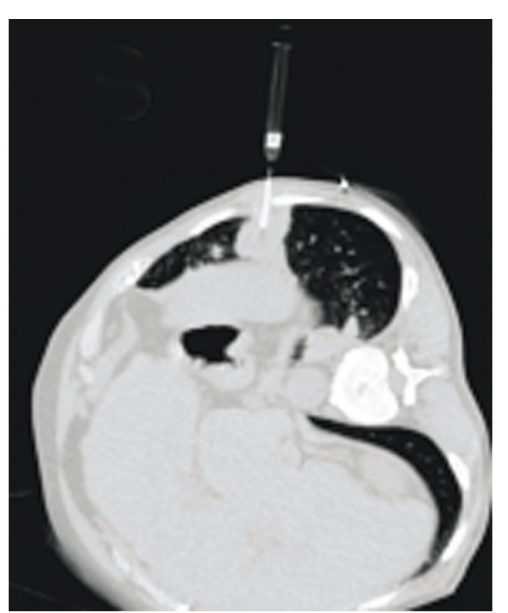

(B)

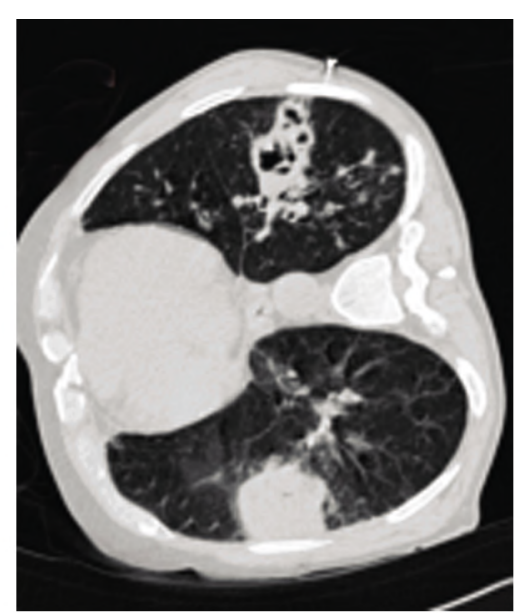

(C)

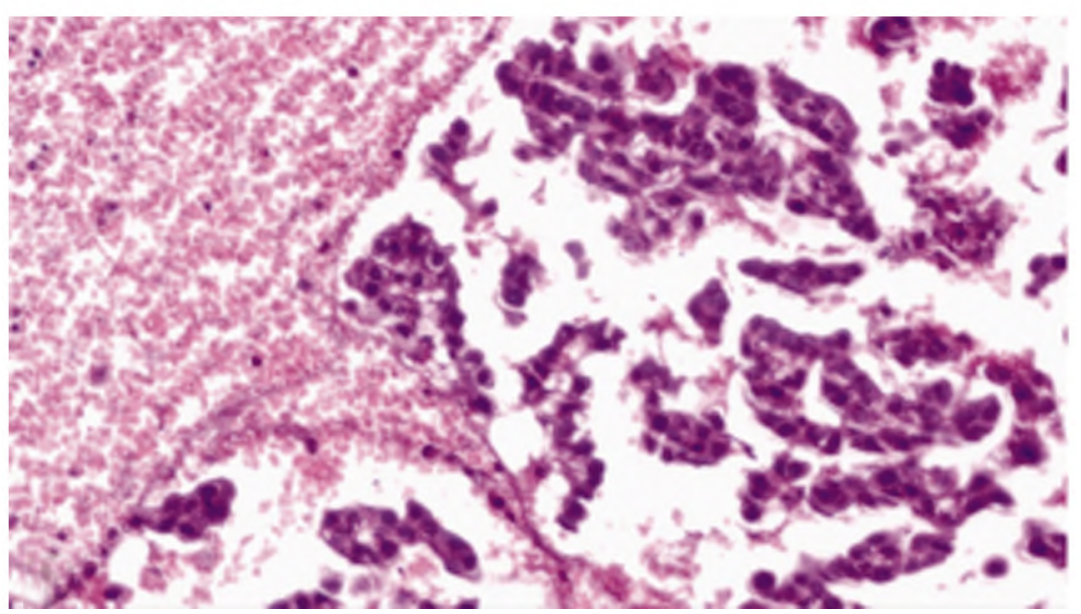

(D)
Fig. (2): 51 years old male patient presented with multiple bilateral cavitary lung lesions FNAB from right side (A) FNAB from left side cavitary lesion (B) Post procedure images revealed no complication (C) Pathological rapid on site evaluation (ROSE) revealed metastatic moderately differentiated adenocarcinoma (D). 

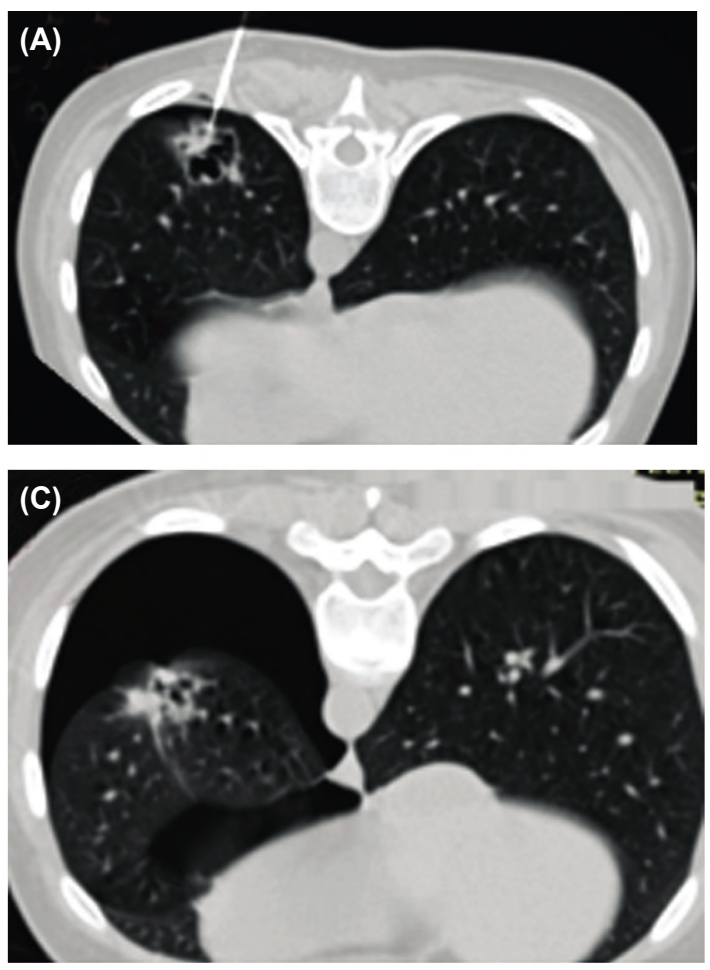
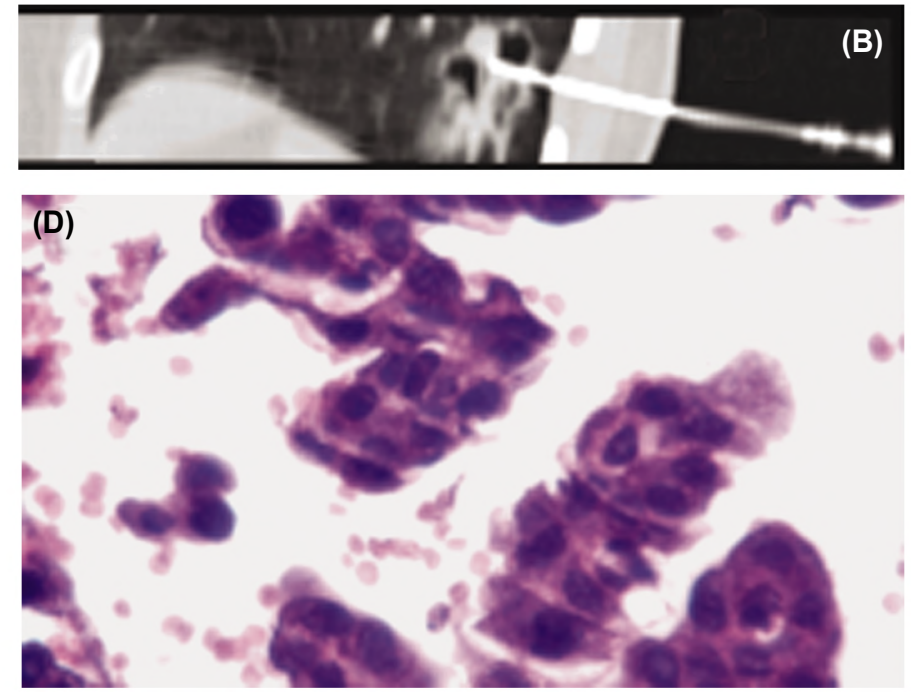

Fig. (3): 25 years old female patient presented with left lower lung lobe thin wall solitary cavitary lung lesion FNAB from the cavity wall the needle was targeted to the maximal wall thickness (A,B) The patient has developed moderate self limited pneumothoracic (C) Pathological rapid on site evaluation (ROSE) revealed adenocarcinoma (D).
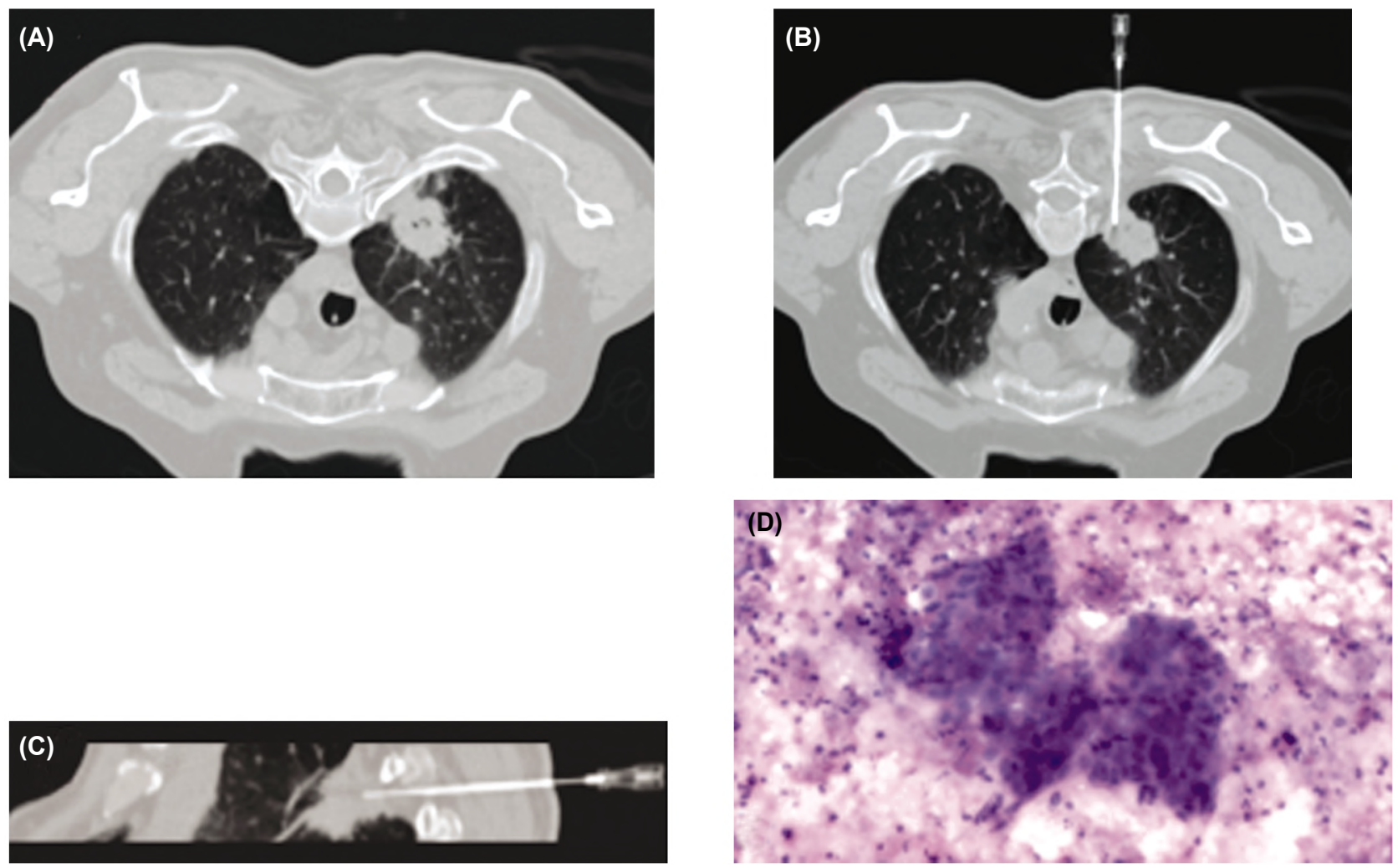

Fig. (4): 53 years old female patient presented with left upper lung lobe cavitating mass (A) FNAB from the cavity wall (B,C) Pathological rapid on site evaluation (ROSE) revealed small cell carcinoma (D). 
10 lesions were found to be specific benign, including:

4 lesions of tuberculosis and

6 lesions of inflammation.

One of them was false negative where it was diagnosed as squamous cell carcinoma on surgery.

3 lesions show non-diagnostic results:

Surgery confirmed one of them as adenocarcinoma however the other two patient were confirmed as tuberculosis on follow-up CT.

3 aspirates microscopically appeared as non specific benign lesions:

2 organizing pneumonia and 1 were confirmed as malignant lesion by surgery.

The sensitivity were $95.1 \%$ (39/41), specificity $90 \%(9 / 10)$, and accuracy of CT guided FNAB for diagnosing the malignancy were and $96.01 \%$ (49/51).

\section{Molecular studies:}

- 6 cases needed molecular studies where cell block paraffin-embedded tissue and the positively charged glass slides which was prepared in the theater were used in all cases Fig. (5).

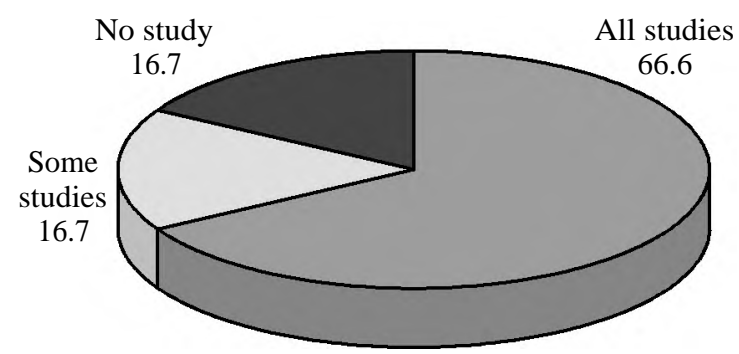

Fig. (5): The adequacy of aspirated material in molecular studies.

- 4 out of them were primary lung NSCLCs and 2 were metastatic tumors.

- In 1 case, adequate tissue was sufficient for some of the needed studies.

- In 4 cases, adequate tissue was sufficient to all of the needed molecular testing.

- Just one case had insufficient material for any of the needed studies.

- ALK and EGFR testing were successfully performed in 4 cases.

\section{Procedure related complications:}

- Post biopsy pneumothoracic occurred in 6 patients $(11.5 \%)$, non of them requiring chest tube.
- One patient developed mild self limited hemoptysis.

- Asymptomatic perilesional hemorrhage was noted by CT at time of biopsy in 5 patients $(9.6 \%)$.

- No related deaths \& no major complications occurred.

\section{Discussion}

In this study we found that $\mathrm{CT}$ guided FNAB in cavitary lung lesions is a rather safe procedure with affordable procedure related complication and accepted accuracy rate depending mainly on co-operation between intervention radiologist and expert pathologist who perform immediate rapid on site examination (ROSE).

The current work shows over all sensitivity $95.1 \%$, specificity $90 \%$, and accuracy of $96 \%$ which match with study done by Loh et al., [8] who interpret that such accepted high values they reached on large scale sample in their study are most likely due to immediate pathological assessment of the specimen.

In this study CT guided FNAB provide good results in cavitary lung lesions with a wall thickness more than $5 \mathrm{~mm}$ matching with study be Nantka et al., [9] who concluded that the increased wall thickness improve the accuracy of biopsy result and the highest diagnostic failure rate was with thin wall cavities.

The recent success in targeted therapy of nonsmall cell lung carcinoma and lung adenocarcinoma [10] push our team to find way out especially when large sample biopsy carry high risk of complication, we concluded that meticulous preparation of malignant aspirates on positive charged glass slides and further adequate aspirates for cell block collection help to provide adequate material for molecular studies.

Barbara et al., [10] subclassified NSCLC using immunostains combined with use of histomorphology matching with our study where molecular analysis including (ALK) and (EGFR) were requested for about $11 \%$ of all the cases in $66.6 \%$ of the cases all requested molecular tests could be done, in $16.7 \%$ the material were sufficient for only some studies while in $16.7 \%$ there was no sufficient material for any test.

\section{Conclusions:}

CT guided fine needle aspiration biopsy of cavitary lung lesion is a safe and accurate procedure while pathological Rapid on Site Evaluation 
(ROSE) can fill the gap between accuracy and adequacy of the small sample aspirates providing adequate material for molecular studies of target therapy.

\section{References}

1- YI-PING ZHUANG, HAI-YAN WANG, JIN ZHANG, et al.: Diagnostic accuracy and safety of CT-guided fine needle aspiration biopsy in cavitary pulmonary lesions, European Journal of Radiology, 82: 182-6, 2013.

2- BESLIC S., ZUKIC F. and MILISIC S.: Percutaneous transthoracic CT guided biopsies of lung lesions; fine needle aspiration biopsy versus core biopsy. Radiology and Oncology, 46 (1): 19-22, 2012.

3- WU C.C., MAHER M.M. and SHEPARD J.A.: Complications of CT-guided percutaneous nee- dle biopsy of the chest: Prevention and management. American Journal of Roentgenology, 196 (6): W678-82, 2011.

4- WU C.C., MAHER M.M. and SHEPARD J.A.: CT-guided percutaneous needle biopsy of the chest: Preprocedural evaluation and technique. American Journal of Roentgenology, 196 (5): W511-4, 2011.

5- LINDEMAN N.I., CAGLE P.T., BEASLEY M.B., et al.: Molecular testing guideline for selection of lung cancer patients for EGFR and ALK tyrosine kinase inhibitors: guideline from the College of American Pathologists, International Association for the Study of Lung Cancer, and Association for Molecular Pathology. Arch. Pathol. Lab. Med., 137 (6): 828-60, 2013.

6- MUKHOPADHYAY S.: Utility of small biopsies for diagnosis of lung nodules: Doing more with less. Mod. Pathol., 25 (suppl1): S43-S57. doi: 10.1038/modpathol. 153. 2012.

7- AISNER D.L. and MARSHALL C.B.: Molecular pathology of non-small cell lung cancer: A practical guide. Am. J. Clin. Pathol., 138 (2): 332-46, 2012.

8- LOH S.E., WU D.D., VENKATESH S.K., et al.: CTguided thoracic biopsy: Evaluating diagnostic yield and complications. Ann. Acad. Med. Singapore, 42 (6): 28590, 2013.

9- NANTAKA KIRANANTAWAT, MILENA PETRANOVIC, SHAUNAGH McDERMOTT, et al.: Feasibility and accuracy of CT-guided percutaneous needle biopsy of cavitary pulmonary lesions, Diagn. Interv. Radiol., 25: 435-41, 2019.

10-BARBARA D. FLORENTINE, M.D.; RICHARD J. HELTON, D.O.; MICHAEL M. MITCHELL, et al.: Accuracy and Adequacy of Computed Tomography-Guided Lung Biopsies: Experience From a Community Hospital, J. Am. Osteopath. Assoc., 115 (10): 592-603. doi: 10.7556/ jaoa.2015.120. 2015.

\title{
دراسة دقة وكفاية خزعة الرئة الموجهة بالآشعة المقطعية لتشخيص آورام الرخئة التجويفية التوجة بالاية
}

\author{
موضوع البحث: أقدام الرئة التجويفيه ليست إكتشافاً إثعاعياً محدداً، خزعة الرئة الموجهة بالآثشعة المقطعية هى طريقة موثوقة لتشخيص

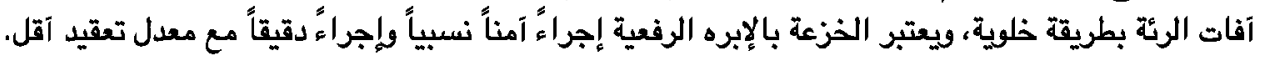

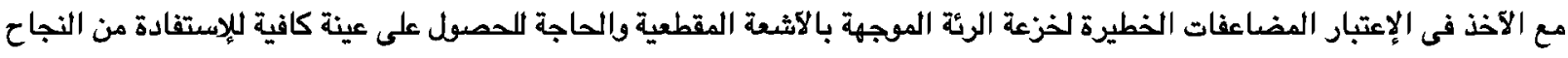

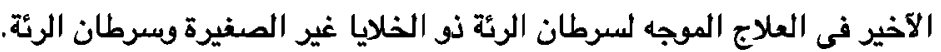 \\ الهدف من الدراسة: الهدف من هذه الدراسة هو تقييم دقة خزعة الإبرة الدقيقة الموجهة بالآشعة المقطعية في الآفات الرئوية التجويفية \\ ووضع معايير تقنية لسد الفجوة بين دقة التشخيص وكفاية خزعة الإبرة الدقيقة الموجهة بالآشعة المقطعية فى الآفات الرئوية التجويفية.

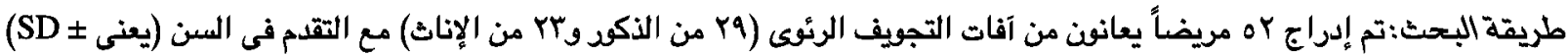

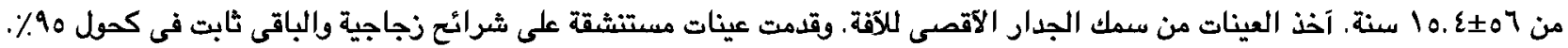

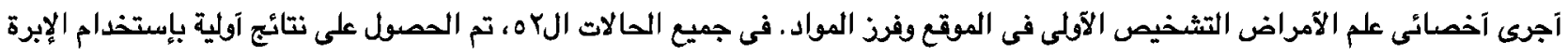

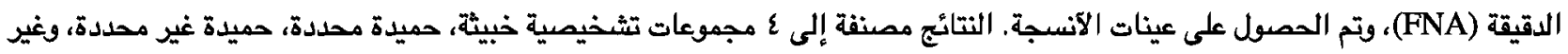

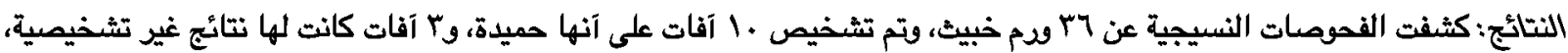

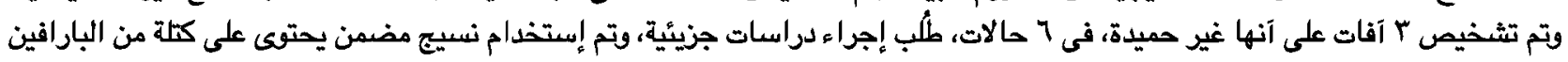

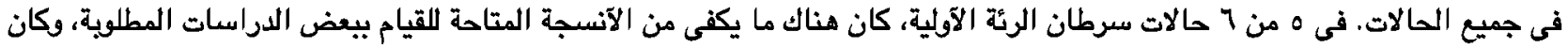

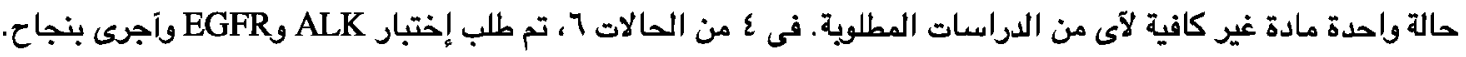

الإستتاج: يوصى بعمل بروتوكول موحد ونهج الفريق لخزعة إبرة الرئة الموجهة بالآشعة المقطعية على تحسين القدرة على تدقيق علة

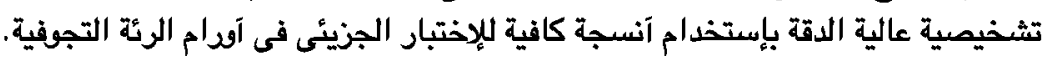

